\title{
A research methodology workshop on 'Social issues in use of medicines' - cooperation between institutions and participant feedback
}

P.R. Shankar ${ }^{1}$, P. Subish ${ }^{2}$, K. Alam ${ }^{3}$

${ }^{1}$ Department of Medical Education, KIST Medical College, Nepal, ${ }^{2}$ Department of Pharmacology, College of Medical Sciences, Bharatpur ${ }^{3}$ Manipal College of Medical Sciences, Pokhara, Nepal

\begin{abstract}
A research methodology workshop on social issues in use of medicines was conducted at Pokhara, Nepal from December $21^{\text {st }}$ to $24^{\text {th }}, 2008$. The present study was conducted to obtain detailed participant feedback about the workshop and obtain suggestions for improvement.

The participants' knowledge was assessed at the start of the workshop and on the final day by noting their agreement with a set of 40 statements using a modified Likert-type scale. The areas of qualitative research, statistics, research methodology, drug use, pharmacovigilance, journal and general were covered. Certain statements were negative and their scores were reversed. The total score was calculated. The median total scores were compared among various subgroups of respondents. Session evaluation was done at the end of each session.
\end{abstract}

A total of twenty-five participants attended the sessions. The workshop significantly improved the median total scores. Significant improvements were also seen in the subcategories Statistics and Journal. The scores of certain statements were low. The evaluation scores of certain sessions were low.

The overall participant opinion about the workshop was positive. Occasional problems with accent of the facilitator and lack of internet access were major problems noted. Some participants felt the workshop was too hectic.

Key words: Nepal, rational use of medicines, research methodology, social issues, workshop.

\section{Background}

The major medicine use problems in Nepal are polypharmacy, excessive use of antibiotics and over use of injections. ${ }^{1}$ Educational initiatives to promote rational use of medicines (RUM) have been carried out. International Network for Rational Use of Drugs (INRUD) Nepal conducts frequent training programmes on rational drug use for faculty members,

Correspondence: P.R. Shankar

E-mail: ravi.dr.shankar@gmail.com health administrators and prescribers at various levels. ${ }^{2}$ Research workshops on 'Social issues in use of medicines' which enable participants to conduct research projects, publish and disseminate the findings and equip them with the skills necessary to intervene to address these problems are however, not common. The workshop was held in December 2008 as collaboration between various institutions in Nepal and 
P.R. Shankar, A research methodology workshop on 'Social issues in use of medicines

abroad. Manipal College of Medical Sciences (MCOMS), Pokhara University (PU), KIST Medical College (KISTMC), Universiti Sains Malaysia (USM), Chualalangkorn University (CU), Thailand and Saba University School of Medicine (SUSM) provided faculty resources for the workshop. MCOMS runs undergraduate and postgraduate programs in Medicine and is involved in training programs for pharmacy students of PU. PU conducts both undergraduate and postgraduate programs in Pharmacy. KISTMC in Lalitpur conducts an undergraduate program in Medicine. Many students from Nepal and other developing countries are pursuing their Masters and $\mathrm{PhD}$ programs in Social Pharmacy at USM. ${ }^{3} \mathrm{CU}$ in Thailand is a well recognized center for studies in Pharmacy. The participants were faculty members from MCOMS, faculty from PU, postgraduates from MCOMS, faculty from KISTMC and other medical schools, pharmacy faculty from Nepal and pharmacists working in the industry.

\section{The objectives of the present study were to:}

a) Obtain basic demographic information about the participants.

b) Compare the median total scores and scores of various individual categories among various categories of respondents.

c) Compare the scores before and after the workshop.

d) Analyze the session evaluations conducted at the end of each session and

e) Obtain suggestions for improvement.

\section{Materials and methods}

The activity-based workshop was conducted from December $21^{\text {st }}$ to December 24 ${ }^{\text {th }}$ 2008. Participants were given adequate time to clarify their doubts. The workshop had the twin objective of introducing participants to social issues in use of medicines and to research methodology.

The participants' knowledge was assessed at the start of the workshop and on the final day after the end of the session using a questionnaire. The order of questions was changed during the posttest. The questionnaire used is shown in the Appendix. Fundamentals of research methodology with special emphasis on medicines use, pharmacoeconomics, pharmacovigilance, social pharmacy, statistics in research and qualitative research methodology were among the various topics covered. Basic demographic information and information regarding research publications were collected. The participants' expectations from the workshop were collected during the pre test. Participants' degree of agreement with a set of 40 statements was measured using a modified Likert-type scale. The statements were grouped together into qualitative research, statistics, research methodology, drug use, pharmacovigilance, journal and general.

The median score and the interquartile range were calculated for each individual statement. Certain statements were negative and their scores were reversed while calculating the median score. The total score was obtained by summing up the scores of individual statements (direct score of the positive and reversed score of the negative statements). The median total scores were compared among various subgroups 
Journal of College of Medical Sciences-Nepal, 2012, Vol-8, No-1

of respondents using Mann-Whitney $U$ test for dichotomous variables and Kruskal Wallis test for others. A p value of less than 0.05 was taken as statistically significant.

Session evaluation was done at the end of each session. The participants' agreement with a set of five statements was measured using a Likert-type scale. Free text suggestions were also invited.

\section{Results}

A total of twenty-five participants attended the sessions. Majority of the participants were male and were pharmacists. Table 1 shows selected demographic characteristics of participants.

Table 2 shows the median total scores and the scores of individual categories before and after the workshop. The median total score before the workshop was 103 and after the workshop it was 107. The increase was significant. Significant improvements were also seen in the subcategories Statistics and Journal.

The scores of statement 3, statement 6 (about the different parts of a research paper), statement 12 (Cronbach's $\alpha$ ), statement 16 (Gantt charts and backward planning charts), statement 21 (starting with Methods section), statement 27 (about INASP), statement 29 (Interquartile range), statements 30 and 31 (dealing with null hypothesis and NHRN), statements 33 and 35 (dealing with TRIPS and indexing services) were low. The reversed scores of statements 1 and 2 (dealing with qualitative research methods and focus group discussions), statement 9 (questionnaire based research), statements 10 and 18 (face validity and Naranjo algorithm), statements 20 and 23 (force field analysis and computer software for qualitative analysis) were also low.

Table 3 shows the median participant feedback scores of various sessions. The scores of the session on Pharmacoepidemiology on day 1, Pharmacoeconomics on day 2 and the national pharmacovigilance program on day 4 were low. The maximum scores were for the session on research proposal, literature research, developing a questionnaire, qualitative research, getting article published and importance of pharmacovigilance in Nepal. The free text suggestions to improve the sessions were regarding the seating of the participants, hard copy of the presentations and group work to be given before the start of the session, and more time for group work and interaction during the sessions. The specific suggestions were at least one effective research proposal as a sample should have been given, which would have given a better opportunity to understand more effectively about the subject 'What is a research proposal?' and the possibility of showing searches live to the participants using an internet connection (Literature research).

\section{Discussion}

The number of female participants was low. A possible reason could have been the four day workshop being conducted in Pokhara and females find it difficult to relinquish their family responsibilities and stay in Pokhara for over five days. A large proportion of the respondents were from outside the Pokhara valley.

The workshop succeeded in improving the scores of the respondents. Before the workshop many participants were not aware about the different parts of a research paper and that Cronbach's alpha could 
P.R. Shankar, A research methodology workshop on 'Social issues in use of medicines

be a measure of internal consistency of a questionnaire.

Participants were also not aware that it is best to start with the Methods section while writing a research paper. Many of the deficiencies noted were improved after the workshop.

The scores of certain sessions were low. Problems of language and understanding the accents of the facilitator/ s could have been partly responsible. The workshop had used separate locations for presentations and for group work. The locations were very nearby but participants had to get up and change places. We felt this will serve as a break and an opportunity for participants to stretch their limbs. The proposal that a sample research proposal be discussed is a good one and we can show it towards the end of the workshop in the future. Internet searches could not be shown live due to technical problems. The hall where the session was held did not have internet connection. Also it was difficult balancing the needs of covering various aspects and topics with keeping the workshop short and focused.

Faculty from various institutions collaborated to organize and conduct the workshop. Despite many limitations, the general organization and the mixture of presentations and small group work was much appreciated by the participants. We plan to hold similar workshops in future and use suggestions obtained to further improve the sessions

\section{Acknowledgements}

The authors acknowledge the contributions of resource persons, Dr. MIM Izham from USM, Dr. Niyada Kiatying-Angsulee from CU, Dr. Pranaya Mishra from SUSM and Dr. Chandrasekhara TS from MCOMS to the workshop.

\section{Conflicts of interest}

The authors declare that they have no competing interests

\section{References}

1. INRUD Nepal. $16^{\text {th }}$ National Training Course on Rational Use of Drugs. 13-18 October 2003. Kathmandu: 2003. Training manual.

2. INRUD Nepal. Available at: http://www.inrudnepal.org.np/. Accessed November $1^{\text {st }}, 2009$.

3. Al-Haddad M, Izham MIM. The Development of the Discipline of Social and Administrative Pharmacy at Universiti Sains Malaysia. Southern Medical Review 2008;1:3-5. 
Journal of College of Medical Sciences-Nepal, 2012, Vol-8, No-1

Table 1: Demographic and personal characteristics of the participants

\begin{tabular}{llc}
\hline Demographic characteristic & Number percentage \\
\hline Gender & Male17 & \\
& Female & 18 \\
Category & Doctor & 6 \\
& Pharmacist, & 17 \\
& PG students (doctors) & 2 \\
Place of work & Kathmandu & 6 \\
& Pokhara & 6 \\
& Others & 10 \\
\hline
\end{tabular}

Table 2: Median total scores and scores of specific individual categories before and after the training workshop

\begin{tabular}{|c|c|c|c|}
\hline Category & & Median score (interquartile range) & Pvalue \\
\hline \multirow[t]{2}{*}{ Total } & Pretest & $103(30.5)$ & \\
\hline & Post test & $107(26)$ & 0.000 \\
\hline \multirow[t]{2}{*}{ Qualitative research } & Pretest & $17(10.5)$ & \multirow{2}{*}{0.324} \\
\hline & Post test & $18(10.5)$ & \\
\hline \multirow[t]{2}{*}{ Statistics } & Pretest & $11(8)$ & \multirow{2}{*}{0.017} \\
\hline & Post test & $11(7)$ & \\
\hline \multirow[t]{2}{*}{ Research methodology } & Pretest & $21(9)$ & \multirow{2}{*}{0.317} \\
\hline & Post test & $21(9)$ & \\
\hline \multirow[t]{2}{*}{ Drug use } & Pretest & $16(7.5)$ & \multirow{2}{*}{1} \\
\hline & Post test & $16(7.5)$ & \\
\hline \multirow[t]{2}{*}{ Pharmacovigilance } & Pretest & $12(3.50)$ & \multirow{2}{*}{1} \\
\hline & Post test & $12(3.5)$ & \\
\hline \multirow[t]{2}{*}{ Journal } & Pretest & $11(7)$ & \multirow{2}{*}{0.000} \\
\hline & Post test & $14(7)$ & \\
\hline \multirow[t]{2}{*}{ General } & Pretest & $15(2)$ & \multirow{2}{*}{1} \\
\hline & Post test & $15(2)$ & \\
\hline
\end{tabular}


P.R. Shankar, A research methodology workshop on 'Social issues in use of medicines

Table 3: Median total participant feedback scores of various sessions

\begin{tabular}{lll}
\hline Day & Topics & Median score (Maximum score 25) \\
\hline Sunday (day 1) & Drug use problems & 21 \\
& Epidemiological research design & 21 \\
& Pharmacoepidemiology & 17 \\
& Research proposal & 24 \\
Monday (day 2) & Pharmacoeconomics & 19 \\
& Literature research & 23 \\
& Developing a questionnaire & 23 \\
Tuesday (day 3) & Basic statistics & 22 \\
& Qualitative research & 23 \\
& Getting article published & 23 \\
& Importance of studying medicine use & 21 \\
Wednesday (day 3) National pharmacovigilance program & 19 \\
& Importance of pharmacovigilance in Nepal & 23 \\
\hline
\end{tabular}

\section{Appendix}

Pre and post test

\section{Workshop on social issues in use of medicines}
Name:
Designation:
Institution:

Category: Doctor/Pharmacist/Post graduate student/Others (please specify) Gender:

Place: $\quad$ Years of experience in profession:

Primary role in institution: $\quad$ No. of research publications: $<10 / 10-50 / 50-100 / 100-200 />200$

Your most influential research paper:

In a maximum of three sentences describe your expectations from the workshop:

For the following statements denote your degree of agreement using the following scale $(1=$ totally disagree with the statement, $2=$ disagree, $3=$ neutral, $4=$ agree and $5=$ totally agree with the statement) 
1. Qualitative research methods are less rigorous compared to quantitative methods.

2. Focus group discussion is a quantitative research method.

3. I have used/plan to use quantitative methods in my research.

4. Content analysis and thematic analysis are important procedures in qualitative research.

5. Methods section is the least important part of a research proposal.

6. IMRaD are the different parts of a research paper.

7. Vancouver style is a method of drawing tables in a research paper.

8. Questionnaire based research is not widely accepted.

9. Face validity is a powerful measure of validity.

10. Polypharmacy is a major drug use problem in Nepal.

11. Calculation of Cronbach's $\alpha$ can be a measure to validate a questionnaire.

12. Pharmacoepidemiology can promote the more rational use of medicines.

13. Validating a questionnaire is difficult in our part of the world.

14. Spontaneous reporting is a commonly used method of pharmacovigilance.

15. Gantt charts and backward planning charts are useful tools for project planning.

16. Medicines can adversely impact the quality of life.

17. Naranjo algorithm is used to measure preventability of an ADR.

18. Pharmacovigilance is a luxury for a developing country like Nepal.

19. Force field analysis is not useful for a research project.

20. It is better to start with the 'Methods' section while writing a research paper.

21. Faculty members should actively encourage research among the students.

22. You do not transfer copyright to the publisher in an open access journal.

23. Percentage of drugs prescribed by generic name is a WHO/INRUD drug use indicator.

24. INASP is an open access research initiative. 
P.R. Shankar, A research methodology workshop on 'Social issues in use of medicines

25. Interquartile range is a measure of dispersion for non-parametric data.

26. Null hypothesis is a hypothesis of no difference.

27. NHRN is a listserv dealing with research issues.

28. Most research studies assess differences at $1 \%$ level of significance.

29. TRIPS and product patents will increase the cost of medicines in South Asia.

30. Social issues in use of medicines are a waste of my valuable time.

31. Indexing services help to access medicines information more easily.

32. Access to HINARI is free in Nepal.

33. This workshop would be useful for my future work.

34. I plan to produce at least one research paper using the information and skills I had learned/will learn in the workshop.

35. I will be interested in attending similar sessions in future.

Thank you for answering the questionnaire. It is highly appreciated. 